\title{
Dyadic Measurement Invariance and Its Importance for Replicability in Romantic Relationship Research
}

\author{
John Kitchener Sakaluk \\ University of Victoria
*Alexandra N. Fisher
University of Victoria

\author{
Robyn E. Kilshaw \\ University of Utah \\ *Connor E. Leshner \\ University of Victoria
}

\begin{abstract}
Comparisons of group means, variances, correlations, and/or regression slopes involving psychological variables rely on an assumption of measurement invariance-that the latent variables under investigation have equivalent meaning and measurement across group. When measures are noninvariant, replicability suffers, as comparisons are either conceptually meaningless, or hindered by inflated Type I error rates. We propose that the failure to account for interdependence amongst dyad members when testing measurement invariance may be a potential source of unreplicable findings in relationship research. We develop fully dyadic versions of invariance-testing in an Actor-Partner Interdependence Model framework, and propose a Registered Report for gauging the extent of dyadic (non)invariance in romantic relationship research.
\end{abstract}

Data, analysis code, supplementary material: https:/osf.io/aw4sr/

Keywords: dyadic data analysis; measurement invariance; replicability; structural equation modeling

The scientific study of romantic dyads has evolved in short order from a relatively niche and straightforward topic, to a booming subfield of interdisciplinary social science that utilizes increasingly sophisticated methods and data analysis strategies. In the shift from oversimplified analyses of individuals in romantic dyadic contexts (e.g., Hill, Rubin, \& Peplau, 1976; Rubin, 1970) to the more complex relationship science of romance that we know today (e.g., Finkel \& Eastwick, 2008; Mancosu \& Vezzoni, 2018; Muise, Christofides \& Desmarais, 2009), the importance of the development and dissemination of dyadic data analysis models (Kenny, Kashy, \& Cook, 2006) cannot be overstated. By enabling researchers to appropriately account for the interdependence of observations within a dyad, analytic paradigms like the Actor-Partner Interdependence Model (APIM; Cook \& Kenny, 2005) and the Common Fate Model (CFM; Ledermann \& Kenny, 2012) have become mainstays of basic relationship science. It also seems as though every year there are

\footnotetext{
* Contributed equally to the preparation of this manuscript. The authors would like to thank the Editors of the Special Issue for facilitating the data collection for this Registered Report, as well as Dr. Amy Muise for her encouragement regarding the importance of dyadic invariance.
}

new extensions to these models (e.g., Gistelinck, Loeys, Decuyper, \& Dewitte, 2018; Ledermann, Macho, \& Kenny, 2011; Loeys \& Molenberghs, 2013) or entirely new models of dyadic processes (e.g., Ledermann \& Macho, 2014; West \& Kenny, 2011) made available, empowering researchers to ask and to answer new questions about romantic relationships. It is an exciting time to be a close relationships scholar.

Yet amidst the excitement of continued methodological development in relationship science, the replication crisis looms large (for reviews see Nelson, Simmons, \& Simonsohn, 2018; Spellman, 2015; Vazire, 2018), and its impact is already being felt within our subfield (Campbell, Loving, \& Lebel, 2014; Cheung et al., 2016; Joel, Eastwick, \& Finkel, 2018). It is surely the case that many well-trodden areas of concern for replicability in general psychology ought to be of concern for relationship science as well (e.g., John, Loewenstein, \& Prelec, 2012; Maxwell, 2004; Rosenthal, 1979; Schimmack, 2012). In the current paper, however, we pursue a different methodological issue yet to be substantively investigated in the context of the replication crisis for either general psychology or relationship science (see Fried \& Flake, 2018, for a discussion). Namely, we consider the issue of measurement invariance (for a review see Vandenberg \& Lance, 2000) and its importance to dyadic data modeling. Dyadic measurement invariance refers to whether it can be reasonably said that a researcher has 
assessed and analyzed the same latent variables for members of the same dyad. We believe dyadic measurement invariance is a core untested-and in some cases, likely faulty-assumption that is essential to the statistical conclusion validity (Shadish, Cook, \& Campbell, 2002) of the various within-dyad comparisons, and substantive theory-testing process (Meehl, 1990a, 1990b; Sakaluk, 2019) upon which much of the romantic relationship literature is based.

In the remainder of the article, we advance the argument that although measurement invariance is of some concern in the context of the broader replicability crisis, we think it is likely a uniquely problematic and impactful issue that undermines the replicability of research on romantic dyads; namely, because dyadic invariance is not usually tested with a fully interdependent analytic approach. We first outline the conceptual issue of measurement invariance and its application as it is most frequently discussed: in the context of between-group comparisons. Using the APIM as an exemplar framework, we then describe how measurement invariance can be imported into the sphere of dyadic data analysis with dependent observations. Acknowledging that many readers may be unfamiliar with this approach, we use the process of testing longitudinal measurement invariance within a latent panel model (Little, 2013) as a source of analytic inspiration. We also briefly consider three motivating rationales for increasing dyadic measurement invariance testing, despite the required (and additional) analytic complexity. Throughout this process, we provide path model visualizations and accompanying analytic code in order to concretize the process of testing dyadic measurement invariance within APIMs, using a variety of scale-setting and model identification configurations. And finally, we conclude with a proposal for a Registered Report in which we would investigate the state of dyadic measurement invariance across a range of relational constructs assessed within the collaborative data collection efforts underlying this special issue.

\section{What Is Measurement Invariance?}

\section{In Concept}

Measurement invariance refers to whether the accuracy of a measuring device is influenced by variation in conditions unrelated to the construct of interest. In psychological research, the constructs of interest are typically abstract and unobservable latent variables, however, Millsap's (2011) analogy to physical measurement is a helpful starting place. Imagine we have a scale designed to measure weight, but its readings depend on an object's shape as well as its weight. If equally weighted but differently shaped objects are consistently assigned unequal values, we would say that the scale produces biased measures of weight as a function of shape. In other words, the scale violates the assumption of measurement invariance.

Extending this concept to the measurement of latent variables, we would say that an assessment violates the assumption of measurement invariance if it produces biased measures based on an unrelated group characteristic. More explicitly, measurement invariance across groups implies the following three things: 1) that the latent variable(s) of interest have the same conceptual meaning in each group; 2) that, regardless of group membership, the latent variable varies in the same systematic way; and 3) that external factors influence the latent variable in the same way across groups (Vanberg \& Lance, 2000). For example, if a measure of relationship satisfaction is invariant across members of romantic heterosexual dyads, it should tap into the same abstract concept in men and women, and a score of $X$ should represent to the same level of relationship satisfaction for both men and women. Furthermore, if daily stressors decrease women's relationship satisfaction by increasing their perceptions of tension within their relationship, then a similar influence of daily stressors should be seen on men's relationship satisfaction (Bodenmann, Ledermann, \& Bradbury, 2007). If these assumptions are met, then finding that men consistently score higher on relationship satisfaction than women can be interpreted as a meaningful group difference in the latent variable. If these assumptions are violated however, it is unclear whether group differences indicate meaningful variation in relationship satisfaction or that the measure is biased by group membership.

Measurement invariance is closely related to other psychometric properties such as validity and reliability. Violation of measurement invariance necessarily implies that the measure has poor validity (i.e., it is not capturing what it purports to be) for one or more groups. Reliability, however, is neither necessary nor sufficient for measurement invariance (Millsap, 2011). A measure that consistently produces similarly biased scores due to group membership can be said to have high reliability but not measurement invariance. In contrast, a measure that captures the same latent variable across groups but produces highly irregular scores over repeated assessment would be deemed unreliable yet invariant across groups. Consequently, the goal in assessing measurement invariance is to determine whether a measure has equivalent validity across groups. In the case of a physical measure such 
as our scale example, the validity across groups could be assessed by comparing repeated measurements from the scale to those obtained from a gold standard (and therefore presumably more accurate, although likely more expensive and time-intensive) measure of weight. With latent variables, however, this strategy is typically not possible. Repeated administration of the same measure of a psychological latent variable is often neither practical (due to cost, time, and placing undue burden on the participant) nor useful (testing effects may change how the participant responds across administrations), and truly unbiased gold-standard measures rarely exist (Millsap, 2011). Consequently, statistical procedures have been developed to determine whether a latent variable satisfies the assumptions of measurement invariance.

\section{In Application}

Measurement invariance can be tested in a number of statistical frameworks (i.e., item-response theory, structural equation modeling, and a combination of the two; see Meade \& Lautenschlager, 2004 for an overview), however, this paper focuses on the structural equation modeling (SEM) approach as it is likely the most readily accessible to all readers. We will describe the three main levels of measurement invariance (i.e., configural, loading, and intercept; Widaman \& Reise, 1997) and how they are tested using confirmatory factor analysis (CFA) and a series of nested model comparisons. Although additional steps (or levels) to invariance testing exist (see Meredith, 1993; Vandenberg \& Lance, 2000), we focus on the three that are required for comparing the magnitude or actor and/or partner effects, as well as comparing partner means on the predictor and/or criterion variable(s). For illustrative purposes, we will use a hypothetical measure of attachment insecurity (Wei, Russell, Mallinckrodt, \& Vogel, 2007; Sibley, Fischer, \& Liu, 2005; Brennan, Clark, \& Shaver, 1998) as an example throughout this section. We will assume that this hypothetical measure is a six-item questionnaire capturing two correlated latent variables, anxiety and avoidance, and that three continuous items load onto each factor (Figure 1). In Figure 1, factor loadings (i.e., slopes of the items regressed onto their respective latent factor(s)) are represented by $\boldsymbol{\lambda}_{\boldsymbol{i 1}}-\boldsymbol{\lambda}_{\boldsymbol{i \mathbf { 6 }}}$ (for $i=1,2$ ), item intercepts (i.e., intercepts of item values when the level of the respective latent factor(s) is 0 ) by $\boldsymbol{\tau}_{\mathbf{1}}-\boldsymbol{\tau}_{\mathbf{6}}$, and item residual variances (i.e., unique true-score variability of other unmodeled factors and error) by $\boldsymbol{\theta}_{\mathbf{1 1}}-\boldsymbol{\theta}_{\mathbf{6 6}}$. In this hypothetical example, the goal is to test whether the measurement models for attachment anxiety and avoidance are invariant across male and female partners in heterosexual romantic dyads, so that we can conduct valid comparisons of structural parameters (e.g., comparing men and women's mean anxiety scores, or comparing the correlation between anxiety and avoidance for men and women).

Configural invariance. Configural invariance is the least restrictive level of equivalence testing and can be thought of as a test of model form across groups (Putnick \& Bornstein, 2016). In other words, configural invariance tests whether the pattern of item loadings is consistent in both groups of interest. In our example, this is equivalent to seeing whether the same items load onto the same latent variables for both men and women (i.e., items 1-3 onto Anxiety and items 4-6 onto Avoidance), without any idiosyncratic crossloadings or omitted loadings. If this model displays acceptable overall fit (see Putnick \& Bornstein, 2016, and Chen, 2007 for discussions of model fit indices), we say that the measure meets the assumption of configural invariance and this becomes our baseline model moving forward. Insufficient model fit, however, would imply that the organization of latent factors and items differs between men and women and the measure is noninvariant across groups.

Loading invariance. The next level of measurement invariance, loading (also referred to as weak or metric) invariance, assesses whether the item loadings are equivalent across groups. In our example, achieving loading invariance, not only implies that the pattern of item loadings is consistent across men and women, but also that the items are comparably associated with their respective latent factors by the same degree in both groups (Putnick \& Bornstein, 2016). If this is the case, we can conduct meaningful tests comparing the magnitude of latent variances, covariances (correlations), and regression slopes between groups (Little, 2013).

To test for metric invariance, item loadings are constrained to be equal across groups (e.g., fixing $\lambda_{11}$ $=\lambda_{21}, \ldots, \lambda_{16}=\lambda_{26}$ ), and overall model fit is compared to that of the unconstrained baseline model (i.e., the model for configural invariance). Evaluating the reasonableness of the loading invariance model (and the levels of invariance thereafter) involves comparing its fit to the baseline model that preceded it. Here, the process of comparing model fit could be approached in a number of ways. Traditional likelihood ratio tests (LRTs; or $\chi^{2}$ difference tests) can be used to determine if the added constraints of loading invariance significantly degrade the fit of model beyond the configural invariance model (Little, 2013), but this method of invariance testing is limited by the concerns 
of sample size sensitivity that undermines the utility of the basic $\chi^{2}$ test of model fit (Brannick, 1995). Other methodologists (e.g., Chen, 2007; Cheung \& Rensvold, 2002) have therefore recommend that researchers examine whether indexes of absolute (or relative) model fit (see Hu \& Bentler, 1999) such as the RMSEA (or CFI) increase (or decrease) beyond some determined threshold, such as $>0.015$ (or $>0.01$ ), which would be taken as evidence of an unacceptable level of model fit degradation.

By whichever standard(s) of model fit a researcher selected, if the fit of the nested weak invariance model is not appreciably worse than the configural invariance model, we would conclude that the measure has met weak invariance across groups, and this model would become our new baseline for comparison. If the overall fit of the weak invariance model was significantly worse, however, this would imply that at least one of the item loadings was not equivalent across groups. Successively unconstraining one loading at a time and assessing the overall fit of each partially constrained model could determine which items were noninvariant. If acceptable model fit was achieved for a partially constrained model, partial loading invariance would be met and this would become the new baseline for comparison.

Intercept invariance. If loading (or partial loading) invariance has been met, the assumption of intercept (also referred to as scalar or strong) invariance can then be tested. Intercept invariance means that the items are expected to have the same predicted value when their corresponding latent variable(s) take on a value of zero. If this is the case, we can conclude that latent factor means are capturing the same amount of variation in each group, and the between-group mean differences are interpretable (Putnick \& Bornstein, 2016). Intercept invariance is tested by keeping the factor loadings constrained as they were in the loading (or partial loading) invariance model, and further constraining the item intercepts to be equal across groups (e.g., fixing $\tau_{1}=\tau_{1}, \ldots, \tau_{6}=\tau_{6}$ ). If only partial invariance was achieved at the previous level, the intercepts of items with unconstrained loadings are also allowed to be freely estimated. This more restrictive model is then compared to the previous baseline model and assessed for overall model fit. In our example, finding that the fit of the intercept invariance model was not significantly worse than that of loading invariance model would imply that scores for anxiety and avoidance have the same meaning for men and women, and that differences in variances, covariances (and correlations), regression slopes and means between groups reflect true differences in the latent variables (as opposed to differing because of nuisance differences in measurement and test construction). As in the case of loading invariance, if the more constrained model displays significantly worse fit than the previous loading (or partial loading) invariance model, partial intercept invariance can be achieved by progressively unconstraining item intercepts (Putnick $\&$ Bornstein, 2016) until sufficient overall model fit is reached. Whether full or partial intercept invariance is achieved, this model would become the new baseline as we move on to comparisons of latent means.

\section{Implications for Replicability}

The implications of measurement practices for the replicability of substantive tests of theory are only beginning to be made explicit (Fried \& Flake, 2018). Nevertheless, there is already a compelling literature to suggest that the failure to establish invariance should lead to unreplicable findings. Indeed, concurrent with contemporary replicability discourse, generalist (Guenole \& Brown, 2014), specialist (Putnick \& Borenstein, 2016; Schmitt, Golubovich, \& Leong, 2011; Chen 2008), and methodology-focused journals (Masyn, 2017; Steinmetz, 2013) have published simulations evidencing the impact of noninvariance for tests of structural parameters.

As the failure to achieve configural invariance renders comparisons of structural parameters (e.g., means, variances, correlations, regression slopes) largely meaningless, configural noninvariance likely poses the most obvious threat to replicability. In the face of configural noninvariance, researchers could still force a comparable structural model across groups (or, equivalently, simply average or sum across items from a factor), and more than likely find some comparisons with significant $p$-values; however, comparing structural parameters in this case would amount conceptually to comparing "apples to spark plugs." (Vandenberg \& Lance, 2000, p. 9) For example, with our hypothetical attachment measure, should a unidimensional model of anxiety fit reasonably well for women, but the pattern of loadings differ appreciably for men (e.g., a two-factor model of anxiety with multiple cross-loadings), there is little to be learned--or replicated--from treating men and women as if they have the same conceptualization of attachment when testing for gender differences in the effects of attachment anxiety.

Moving further up the ladder of invariance testing, should configural invariance between groups be established, but loading and/or intercept invariance fail, then there is still a negative impact on future replicability. Specifically, when loading and/or intercept invariance are not tenable, error rates for comparisons of structural parameters "can greatly 
deviate from the nominal $\alpha=.05$," (Masyn, 2017, p. 187) resulting in "bogus interaction effects" and "pseudo group differences" (Chen, 2008, p. 1005). The extent of this biasing depends on a number of factors, including the measurement parameter type (loading vs. intercept), the structural comparison type (e.g., mean differences vs. regression slope differences), measurement model complexity, the extent the magnitude of noninvariance, and the extent of partial invariance, amongst others (Chen 2008; Guenole \& Brown, 2014; Masyn, 2017; Putnick \& Borenstein, 2016; Schmitt et al, 2011; Steinmetz, 2013). In the field of close relationships, the impact for ignoring variability in measurement on the replicability of findings is therefore not a question of "if?", but rather of "how much?"

\section{Extending Invariance Testing to the Dyadic Context}

Measurement invariance is a tacit assumption that pervades many of the statistical comparisons dyadic analysts would wish to make. Take, for example, a generic (non-latent) APIM with distinguishable members (Cook \& Kenny, 2005) predicting $Y$ from $X$ (see Figure 2). A researcher modeling this pattern of dyadic interdependence might not only be interested in estimating separate actor $(a 1, a 2)$ and partner effects $(p 1, p 2)$, but also in: (1) comparing actor and/or partner effects (e.g., are actor effects comparable between two dyad members?); and (2) comparing partners' standings on either $X$ and/or $Y$. The validity of these comparisons relies doubly on the soundness of measurement invariance, as invariance must be present for both $X$ and for $Y$ variables.

In comparing analytic strategies for dyadic modeling, Ledermann and Kenny (2017) offer the ability to evaluate measurement invariance as one of the strengths of a structural equation modeling (SEM) approach. Further espousing the virtues of SEM for fitting dyadic models like the APIM, Ledermann and Kenny (2017) point to the example of South, Krueger, and Iacono (2009), in which the authors, “...estimated a CFA model to test invariance across partners for Spanier's (1976) Dyadic Adjustment Scale.” (p. 448) Upon closer inspection, however, the invariance tests conducted by South and colleagues (2009) appear to ignore the interdependence in observations among dyad members. From the description of their analytic approach:

To account for possible non-independence of the data (i.e., both spouses are reporting on the same marriage), we modeled the data at the couple level (both husbands and wives were on the same line of data). The factor model for husbands and wives was connected through a correlation between the higher order latent factors. (South et al., 2009, p. 624).

There are two misunderstandings in this description worth clarifying. The first is that using a couple-level data structure somehow accounts for the dependency among observations between members of a dyad. Although a dyad-level dataset is the necessary data structure for specifying an APIM in an SEM framework (Kenny et al., 2006) - it does nothing to directly model the interdependence. Similarly, it is a misconception that correlating the latent factors across partners would address the dependency among observations between partners. This strategy is no more effective at accounting for dependency than correlating $X$ terms in an APIM would. Instead, interdependence requires the correlating of error terms (both at the measurement model and structural model levels) between partners, in order to appropriately specify.

This process of specifying dependency is generally identical to how dependency is specified in latent longitudinal models (see Little, 2013), in which error terms for repeated assessments of the same items for a given factor are correlated (e.g., the first item assessing anxiety at Time 1 , Time 2 , and Time 3 , in a hypothetical 3-wave longitudinal study of attachment). And likewise, just as invariance can (and should) be be tested between groups, so to can (and should) it be tested across time - or other dependency-introducing design features, like dyadic data - in order to ensure the latent variable(s) under consideration retain their meaning, and that structural comparisons are thereby meaningful.

\section{Dyadic Invariance Modeling}

After accounting for the interdependency of observations by correlating the appropriate measurement-model error terms (e.g., $\boldsymbol{\theta}_{11}$ and $\boldsymbol{\theta}_{55}, \boldsymbol{\theta}_{22}$ and $\left.\boldsymbol{\theta}_{66} \ldots\right)$ and structural-model error terms (i.e., $\boldsymbol{\Psi}_{33}$ and $\left.\boldsymbol{\Psi}_{44}\right)$, researchers would then incrementally increase constraints on measurement parameters in the normal invariance testing sequence (Putnick \& Bornstein, 2016). Figure 3 - Figure 5 provide exemplar path diagrams for the appropriate specification of dyadic configural, loading, and intercept invariance.

In specifying a properly interdependent latent APIM - and so long as the pattern of observed variables loading onto latent variables remains the same for both partners - a researcher will have already imposed dyadic configural invariance (Figure 3). Researchers would then evaluate the fit of this model 
based on the usual criteria (Hu \& Bentler, 1999; Bollen \& Long, 1993), and provided acceptable fit, it would become the initial baseline model for subsequent dyadic invariance testing models.

By building off of the dyadic configural model to also constrain loadings for the same item across partners to equivalency, Hong and Kim (2018) appear to provide one of the first examples of properly testing dyadic loading invariance (see their Model 3). If the constraints of the dyadic loading invariant model were reasonable when compared to the dyadic configural invariance model, researchers would use this model as the new baseline model. Specifically, this model would serve as a basis for valid comparisons of latent actor and/or partner effects between dyad members, and for the subsequent test of dyadic intercept invariance. Dyadic intercept invariance, finally, would require researchers to equate intercept terms for the same items across partners, and this model would serve as a baseline for valid comparisons of latent means on the $X$ and $Y$ variables between partners.

\section{Why Bother?}

It is fair to say that the implementation of properly specified dyadic invariance testing will increase analytic demands on scholars who rely on dyadic analyses. Even so, we can think of three primary reasons why there is value in rising to the analytic challenge of implementing properly specified dyadic invariance models in our field.

Interdependence matters. Some readers might view our call to increase dyadic invariance modeling as overburdensome and unnecessary in light of the extent to which close relationship researchers already evaluate invariance using multi-group confirmatory factor analysis approaches (e.g., Karantzas, Feeney \& Wilkinson, 2010; Maxwell et al., 2017; Schrodt et al., 2009; Whisman \& Li, 2015). Although we agree it is a good thing that relationship researchers have made efforts to establish the invariance of the measurement structures upon which they rely, we have already described how this process fails to take the interdependent nature of dyadic data into account during the invariance testing process. If analytic errors are made in the process of testing dyadic invariance, then the lesser-worst-case scenario is the Type I error rates of subsequent structural tests will be inflated (McCoach \& Adelson, 2010). On the other hand, the worst-worst case is that fundamentally different latent variables are involved, and these structural tests will be entirely meaningless (Vandenberg \& Lance, 2000). We should not be surprised when previous effects beset by either possibility fail to replicate.

Beyond the negative impact on replicability, ignoring dependency in the process of invariance testing is also at-odds with the zeitgeist of data analysis in close relationships research. Indeed, dyadic data analysis methods rose to prominence not simply because dependency presents a statistical nuisance that must be addressed (as it certainly does), but rather, because enough researchers in the field found matters of interdependence theoretically interesting in their own right. If one were to list some of the central assumptions researchers in our field are comfortable making, that interdependent contexts change patterns of thought, feeling, and behavior would have to top the list. Continuing to evaluate invariance in measures with methods that ignore dependency is therefore not only statistically ill-advised (and ultimately compromising of replicability), it is also incongruent with the fundamental ways in which our field understands relational psychology and behavior. If the dyadic context matters for how people experience the world, and modeling interdependence matters for the valid estimation of dyadic effects, then there is no escaping how dyadic context and modeling interdependence should also matter for evaluating measurement invariance among dyad members.

The default of distinguishability. The typical ways in which close relationship researchers model their dyadic data - their analytic norms - present another reason for the adoption of dyadic invariance testing. Dyadic models like the APIM present researchers with a choice: to model the members of dyads as either indistinguishable or distinguishable from one another in some important way. In the context of research on heterosexual romantic couples, gender/sex (see van Anders, 2015 for the meaning of this term) is easily the most common distinguishing variable used, such that separate levels of $X$ and $Y$, and separate actor and partner effects (along with other parameters) are estimated for men and women. Although numerous strategies are available for statistically testing distinguishability of actor-partner effects (Olsen \& Kenny, 2006; Gistelinck, Loeys, Decuyper, \& Dewitte, 2018), it is safe to say-at least in the context of dyadic studies on heterosexual romantic relationships - that the majority of researchers anticipate that men and women will somehow be different in terms of the variables of interest and the patterns of association between them, and without always testing this assumption directly, default to modeling dyad partners as distinguishable (cf. Kenny et al., 2006). But if dyadic researchers are so bullish on the prospect of differences between distinguishable members of a dyad, why 
would they be bearish on measurement structures, and presume dyad partners (e.g., men and women) to have entirely similar ways of conceptualizing the processes researchers are studying? If anything, it would be more congruent for dyadic researchers to likewise anticipate that distinguishable dyad members have some nonnegligible differences in their meanings of psychological and relational concepts.

Incorporating regular dyadic invariance testing would therefore help to bring dyadic researchers' analytic norms into better alignment with the ways in which they think about measurement, resulting in a more coherent process of theorizing and analyzing dyadic interdependence. Should dyadic invariance testing reveal frequent and/or important differences in measurement and conceptualizations between dyad members, it would complicate how dyadic researchers would need to proceed to test their structural parameters of interest. However, it would also supply dyadic researchers with a new kind of outcome of interest, as differences in measurement needn't be thought of exclusively as a mere analytic annoyance, but could - and should - be viewed as a substantively meaningful analytic outcome in its own right (see Sakaluk, 2019).

Capacity for change. Our final reason in motivating for increased dyadic invariance testing reflects our optimism in the methodological capacity of the field of dyadic researchers. Although barely 10 years old, contemporary cross-sectional models of dyadic interdependence (Kenny et al., 2006) have already undergone considerable revision and expansion. All the while, the field of dyadic researchers have kept pace. Researchers incorporating dyadic tests of moderation (Campbell \& Kashy, 2002) and/or mediation (Ledermann, Macho, Kenny, 2011), and/or analyzing patterns of dyadic effects in complex longitudinal designs (Bolger \& Laurenceau, 2013) are not the exception; they are the rule, in spite of the added complexity these analyses demand. And so, while we continue to acknowledge the added burden and complication that properly implementing dyadic invariance models will require, we simultaneously see there being considerable benefits to the credibility of our research in doing so, and believe that the field of dyadic researchers are up to the challenge.

\section{Locating Dyadic Variability in Measurement}

Past research hints that dyadic researchers are not only up to the challenge but acutely interested in considerations of dyadic invariance and noninvariance between men and women in romantic relationships.
Considerable empirical attention has been given to the examination of gender differences in both the subjective meaning and experience of various relational constructs such as marital quality, communication, and romantic jealousy, among others (e.g., Beam et al., 2018; Wheeler, Reis, \& Nezlek, 1983; Tan, Jarnecke, \& South, 2017; Zandbergen \& Brown, 2015). Moreover, assumptions of noninvariance between men and women are inherent in the scientific discourse surrounding 'his and her' marriages (e.g., Kiecolt-Glaser \& Newton, 2001; Stokes, 2017). Thus, it would appear that the time is ripe for dyadic researchers to put well-established and commonly-used measures of romantic relationship processes to the test in a dyadic framework. Specifically, we propose that dyadic invariance testing has the potential to enrich and extend scientific understanding and measurement in three key domains: relationship well-being (e.g., relationship quality, commitment, satisfaction), relationship personality (e.g., attachment, communal strength), and sexuality (e.g., sexual motivation, sexual satisfaction). In the following sections, we provide brief examples of why and how dyadic invariance may be particularly important and/or (un)likely in each of these domains of romantic relationship measurement.

\section{Relationship Well-Being}

Oft-used measures of relationship quality such as the Perceived Relationship Quality Components (PRQC) Inventory (Fletcher, Simpson, \& Thomas, 2000) typically rest on the assumption that romantic relationship quality is composed of the same components (e.g., love, trust, intimacy, satisfaction, commitment, and passion) for both men and women alike, and that each of these components contribute similarly to men and women's relational well-being. Yet, when evaluating the quality of their relationships, men have been found to place greater value on the role of passion than do women (Fehr \& Broughton, 2001). Conversely, women tend to place greater emphasis on commitment and intimacy in a relationship (Sprecher, 2002; Sternberg, 2006). These findings suggest that men and women may differ in their subjective assessments of relationship quality.

\section{Relationship Personality}

Dyadic measurement invariance is also an important consideration for measures of relationship-related elements of personality. For example, communal strength is conceptualized as the degree to which an individual is motivated to be responsive to a partner's 
needs (Mills, Clark, Ford, \& Johnson, 2004). Critically, however, traditional gender roles prescribe that women should be more communal and relationally-focused than men and that men should be more agentic and individually-focused than women (e.g., Eagly \& Wood, 1999). Men and women's motivations to be responsive to their partners' needs are likely shaped by these broader gender-role expectations. Indeed, women do tend to be more relationally-focused (e.g., Cross \& Madson, 1997), as well as more attuned and responsive to the emotional needs of their partners than men (Croyle \& Waltz, 2002; Neff \& Karney, 2005). Thus, what it means to be a highly responsive partner may shift depending on whether one is a man or a woman. Consequently, a man who is highly responsive to the emotional needs of his partner may demonstrate higher communal strength relative to other men, yet he may still fall short when compared to the communal strength of the average woman.

\section{Sexuality}

Perhaps the most obvious case for the necessity of testing for dyadic measurement invariance comes from the literature highlighting various gender differences in sexual motivation and sexual satisfaction. For example, in long-term relationships, women's primary motivations for engaging in sex tend to be emotional whereas men's primary motivations tend to be physical (e.g., Armstrong \& Reissing, 2015; Vohs, Catanese \& Baumeister, 2004). Accordingly, women tend to report a wider range of motivations for engaging in sex compared to men (Stephenson, Ahrold, \& Meston, 2011). Women's motivations for engaging in sex are also more likely to change over time whereas men's motivations tend to remain stable across the life course (Gebauer, Baumeister, Sedikides \& Neberich, 2014). These findings call into question whether invariance in both the structure and nature of men and women's sexual motivations can be reasonably assumed.

Men and women also appear to differ in how they conceptualize and evaluate their own sexual satisfaction. For instance, men tend to report experiencing greater pleasure from sexual activities such as penile-vaginal intercourse and giving/receiving oral sex compared to women (e.g., Haavio-Mannila \& Kontula, 1997; Galinsky \& Sonenstein, 2011; Holmberg \& Blair, 2009; Pinkerton, Cecil, Bogart \& Abramson, 2003). Yet, other research has found that women consistently report higher sexual satisfaction than men (e.g., Sprecher, 2002). Upon first pass, these findings might seem contradictory. However, one possible explanation for this seeming contradiction is that men and women may employ a different set of criteria when evaluating their sexual satisfaction. In support of this account, men report that achieving orgasm is of primary importance to their sexual satisfaction whereas women consider achieving orgasm to be more of a 'bonus' rather than the primary determinant of their sexual satisfaction (Salisbury \& Fisher, 2014, p. 620).

\section{Summary}

Ultimately, the above examples serve mainly to highlight what close relationship researchers already seem to intuit: that dyadic invariance in measures of relationship well-being, relationship personality, and sexuality cannot and should not reasonably be assumed. As for those who remain skeptical, we hope these examples will raise even the slightest of doubts about the tenability of dyadic invariance in relational domains and, in doing so, demonstrate that at the very least dyadic invariance warrants further consideration. Above all, we hope these examples have demonstrated that dyadic researchers are perfectly poised to consider and tackle issues of dyadic invariance within their own research. Doing so will improve the credibility of our science by empowering researchers to draw more meaningful, and more accurate, inferences about dyadic processes.

\section{The Proposed Registered Report}

When measures are noninvariant, inferential comparisons of dyadic structural coefficients like actor and partner effects are either biased or conceptually meaningless. As we have argued, properly specified tests of dyadic invariance have largely been absent from the close relationship literature (cf. Hong \& Kim, 2018), and therefore, a crucial auxiliary theory of research on romantic relationships has gone untested (Fried \& Flake, 2018; Meehl, 1990a, 1990b; Sakaluk, 2019). Dyadic variability in measurement may therefore serve as a potent and wide-spread undermining factor of the replicability of close relationship research.

The dyadic data collection facilitated by the Editors of the Special Issue presents a rare opportunity to gauge the extent to which measurement models in heterosexual romantic relationships are invariant between distinguishable partners, across a range of latent variables of broad interest to the field. We therefore propose to test dyadic configural, loading, and intercept invariance in APIMs across measures used in the shared dyadic data sets of the Special Issue. 


\section{Proposed Methods}

\section{Participants}

Participants will be members of romantic couples recruited via the Editors collaborative data collection efforts of ten dyadic samples for the Special Issue, collected via Qualtrics Panels. Since dyadic sample sizes will vary from invariance test to invariance testas in cases where the identical measure (e.g., a common measure of relationship quality) is present in multiple samples-we will conduct our invariance tests combining across these samples. Minimum sample sizes for dyadic invariance tests will be at least 200 spousal dyads. Although statistical power requirements for testing invariance in the dyadic context are not well understood, invariance tests involving at least 400 distinguishable members would be well above the norm for typical recommendations of sample sizes needed for invariance testing in other analytic contexts involving dependent observations (see Little, 2013).

\section{Measures}

The available measures will largely be dictated by the interests of those granted one of the dyadic samples collected by the Editors. However, given the collection of data from romantic dyads, we have identified types of measures - and specific examples - that we would find interesting and important for the purpose of evaluating dyadic invariance (see Table 1). We will also test invariance for any measure identified as central to a research team's dyadic analysis, even if that measure(s) falls outside the scope of the three broad types of measures that we have identified.

\section{Data Analysis Strategy}

Measurement models for invariance will be determined either based on available measurementrelated papers for the measures in question, or based on researcher scoring decisions (e.g., we would model all items as loading onto a factor that a researcher described as averaging together into one composite); we think that in the majority of cases, it is likely that both strategies will be aligned in their implications for the measurement model we specify. All invariance analyses will be conducted in $R$ (R Core Team, 2018) using the lavaan (Rosseel, 2012) and semTools (Jorgensen, Pornprasertmanit, Schoemann \& Rosseel, 2018) packages. When indicator variables have more than four ordered response options--a case we anticipate for the vast majority of latent variables we analyze--we will estimate our models using a maximum likelihood estimator that is robust to nonnormality (mlr; see Bischl, Lang, Kothof, Schiffner,
Richter, Studerus, Casalicchio \& Jones, 2016; ). When indicator variables have fewer than four ordered response options, or involve nominal responses, we will use a categorical estimator that is robust to nonnormality (ULSMVS; see Rhemtulla, Brosseau-Liard, \& Savalei, 2012). Finally, whenever possible, we will use full-information maximum likelihood to handle missingness in participant responses, and thereby minimize estimation bias and lost statistical power (Enders, 2010).

All invariance tests will be conducted within a latent APIM framework (as in Figures 3-5). Other dyadic models can be fit (e.g., Ledermann \& Kenny, 2012) to the same kind of dyadic data, using latent variable analyses, and may be preferred among researchers testing other substantive questions. The matter of invariance, however, remains an important assumption and auxiliary theory baked into any dyadic model, and the APIM presents a straightforward means of evaluating it. Given the APIM's relative popularity, we will pursue this formulation of dyadic invariance testing to achieve a consistent invariance testing strategy across measures.

Three final interrelated analytic details require a more nuanced unpacking: (1) the distinction between measurement model adequacy and configural invariance; (2) the matter of evaluating model fit; and (3) the matter of managing model complexity. Regarding the first matter, as Jorgensen and his colleagues (Jorgensen, Kite, Chen, \& Short, 2017) have aptly identified, the traditional way of evaluating the reasonableness of configural invariance conflates the of process configural invariance testing with that of assessing the fit of the underlying model, irrespective of invariance. As methods for disentangling the two issues are only just emerging, it is important to acknowledge that our proposed investigation will be limited in this way too. In other words, the measures we evaluate for dyadic invariance may fail the configural invariance check not because the factor structure is different for one member of the dyad or the other, but simply because the measurement model may not be well-fitting for either dyad.

Regarding the second matter, and in response to the conflation of basic model fit and configural invariance tenability, we propose descriptively interpreting the comparability of factor solutions between dyad members, even when the fit of the overall model is not acceptable. Comparisons of stricter levels of invariance (e.g., dyadic loading invariance) to baseline models (e.g., dyadic configural invariance) will rely on interpretations of changes in RMSEA and CFI (Chen, 2007; Cheung \& Rensvold, 2002), although we will also note when LRTs indicate a significant decrease in 
fit as well. Although a measure with a generally poorfitting model should also not be expected to produce replicable findings, this process will help to distinguish between two potential sources of unreplicable findings: poor fitting measurement models in general, and differing measurement models between dyad members.

Finally, regarding the second matter, in some cases the measures used by researchers published in the Special Issue may be quite elaborate, with many items loading onto many factors. In some cases, exceptionally complex models can cause estimation problems, or yield poor fit simply because the underlying measurement model is not sufficiently parsimonious (Brown, 2015). In cases such as these, our analytic contingency plan is to create a maximum of five parcel-indicators per factor (Little, Cunningham, Shahar, \& Widaman, 2002), using the bias-minimizing random item-to-parcel allocation strategy (Sterba, 2011; Sterba \& MacCallum, 2010). The resulting measurement model would be overidentified, providing us some (less generalizable) ability to evaluate general model fit, while also enabling us to test the subsequent levels of measurement invariance.

We will report our results in an accessible summary table styled in the manner of Table 2. However, we will also provide a more detailed supplementary table of results for all dyadic invariance tests (along with our reproducible analytic syntax), including all individual model fit indexes, LRTs, and changes in model fit indexes between levels of invariance.

\section{References}

Armstrong, H. L., \& Reissing, E. D. (2015). Women's motivations to have sex in casual and committed relationships with male and female partners. Archives of Sexual Behavior, 44(4), 921-934. https://doi.org/10.1007/s10508-014-0462-4

Beam, C., Marcus, K., Turkheimer, E., \& Emery, R. (2018). Gender differences in the structure

of marital quality. Behavior Genetics, 48(3), 209-223. doi:10.1007/s10519-018-9892-4

Birnbaum, G. E., Mikulincer, M., Szepsenwol, O., Shaver, P. R., \& Mizrahi, M. (2014). When sex goes wrong: A behavioral systems perspective on individual differences in sexual attitudes, motives, feelings, and behaviors. Journal of Personality and Social Psychology, 106(5), 822-842. https://doi.org/10.1037/a0036021

Bischl, B., Lang, M., Kotthoff, L., Schiffner, J., Richter, J., Studerus, E., Casalicchio, G., \& Jones, Z. (2016). "mlr: Machine Learning in R." Journal of Machine Learning Research, 17(170), 1-5. http://jmlr.org/papers/v17/15-066.html.

Bodenmann, G., Ledermann, T., \& Bradbury, T. N. (2007). Stress, sex, and satisfaction in marriage. Personal Relationships, 14(4), 551-569. https://doi.org/10.1111/j.1475-6811.2007.00171.x
Bolger, N., \& Laurenceau, J. P. (2013). Intensive longitudinal methods: An introduction to diary and experience sampling research. New York, NY: Guilford Press.

Bollen, K. A., \& Long, J. S. (1993). Testing structural equation models. (K. A. Bollen \& J. S. Long, Eds.). Thousand Oaks, CA: Sage Publications, Inc

Brannick, M. T. (1995). Critical comments on applying covariance structure modeling. Journal of Organizational Behavior, 16, 201-213.

Brennan, K. A., Clark, C. L., \& Shaver, P. R. (1998). Self-report measurement of adult romantic attachment: An integrative overview. In J. A. Simpson \& W. S. Rholes (Eds.), Attachment theory and close relationships (pp. 46-76). New York: Guilford Press.

Brown, T. A., \& Little, T. D. (2015). Confirmatory factor analysis for applied research. New York, NY: The Guilford Press.

Buss, D. M., Shackelford, T. K., Kirkpatrick, L. A., Choe, J. C., Lim, H. K., Hasegawa, M., ... Bennett, K. (1999). Jealousy and the nature of beliefs about infidelity: Tests of competing hypotheses about sex differences in the United States, Korea, and Japan. Personal Relationships, 6(1), 125-150. https://doi.org/10.1111/j.1475-6811.1999.tb00215.x

Buss, D. M., Larsen, R. J., Westen, D., \& Semmelroth, J. (1992). Sex differences in jealousy: Evolution, physiology, and psychology. Psychological Science, 3(4), 251-255. https://doi.org/10.1111/j.1467-9280.1992.tb00038.x

Campbell, L., Loving, T. J., \& Lebel, E. P. (2014). Enhancing transparency of the research process to increase accuracy of findings: A guide for relationship researchers. Personal Relationships, 21(4), 531-545. https://doi.org/10.1111/pere.12053

Campbell, L., \& Kashy, D. A. (2002). Estimating actor, partner, and interaction effects for dyadic data using PROC MIXED and HLM: A user-friendly guide. Personal Relationships, 9(3), 327342. https://doi.org/10.1111/1475-6811.00023

Chen, F. F. (2008). What happens if we compare chopsticks with forks? The impact of making inappropriate comparisons in cross-cultural research. Journal of Personality and Social Psychology, 95(5), 1005-1018. https://doi.org/10.1037/a0013193

Chen, F. F. (2007). Sensitivity of goodness of fit indexes to lack of measurement invariance. Structural Equation Modeling, 14(3), 464-504. https://doi.org/10.1080/10705510701301834

Cheung, I., Campbell, L., LeBel, E. P., Ackerman, R. A., Aykutoğlu, B., Bahník, š., ... Yong, J. C. (2016). Registered Replication Report: Study 1 From Finkel, Rusbult, Kumashiro, \& Hannon (2002). Perspectives on Psychological Science, 11(5), 750-764. https://doi.org/10.1177/1745691616664694

Cheung, G. W., \& Rensvold, R. B. (2002). Evaluating goodness-offit indexes for testing measurement invariance. Structural Equation Modeling, 9(2), 233-255.

Cook, W. L., \& Kenny, D. A. (2005). The Actor-Partner Interdependence Model: A model of bidirectional effects in developmental studies. International Journal of Behavioral Development, 29(2), 101-109. https://doi.org/10.1080/01650250444000405 
Cross, S. E., \& Madson, L. (1997). Models of the self: Selfconstruals and gender. Psychological Bulletin, 122(1), 5-37. https://doi.org/10.1037/0033-2909.122.1.5

Croyle, K. L., \& Waltz, J. (2002). Emotional awareness and couples' relationship satisfaction. Journal of Marital and Family Therapy, 28(4), 435-444. https://doi.org/10.1111/j.17520606.2002.tb00368.x

Eagly, A. H., \& Wood, W. (1999). The origins of sex differences in human behavior: Evolved dispositions versus social roles. American Psychologist, 54(6), 408-423. https://doi.org/10.1037/0003-066X.54.6.408

Enders, C. K. (2010). Applied missing data analysis. New York, NY: Guilford Press.

Fehr, B., \& Broughton, R. (2001). Gender and personality differences in conceptions of love: An interpersonal theory analysis. Personal Relationships, 8(2), 115-136. https://doi.org/10.1111/j.1475-6811.2001.tb00031.x

Finkel, E. J., \& Eastwick, P. W. (2008). Speed-dating. Current Directions in Psychological Science, 17(3), 193-197. https://doi.org/10.1111/j.1467-8721.2008.00573.x

Fisher, W. A., Byrne, D., White, L. A., \& Kelley, K. (1988). Erotophobia-erotophilia as a dimension of personality. Journal of Sex Research, 25(1), 123-151. https://doi.org/10.1080/00224498809551448

Fletcher, G. J. O., Simpson, J. A., \& Thomas, G. (2000). The measurement of perceived relationship quality components: A confirmatory factor analytic approach. Personality and Social $\begin{array}{llll}\text { Psychology Bulletin, } & \text { 26, 340-354. }\end{array}$ doi:10.1177/0146167200265007

Fried, E. I., \& Flake, J. K. (2018). Measurement Matters [Web log post]. Retrieved from https://www.psychologicalscience.org/observer/measurementmatters

Funk, J. L., \& Rogge, R. D. (2007). Testing the ruler with item response theory: Increasing precision of measurement for relationship satisfaction with the Couples Satisfaction Index. Journal of Family Psychology, 21(4), 572-583. https://doi.org/10.1037/0893-3200.21.4.572

Galinsky, A. M., \& Sonenstein, F. L. (2013). Relationship commitment, perceived equity, and sexual enjoyment among young adults in the United States. Archives of Sexual Behavior, 42(1), 93-104. https://doi.org/10.1007/s10508-012-0003-y

Gebauer, J. E., Baumeister, R. F., Sedikides, C., \& Neberich, W. (2014). Satisfaction-Adaptation Principles in Sexual Desire: Exploring Gender Differences Across the Life Span. Social Psychological and Personality Science, 5(2), 176-184. https://doi.org/10.1177/1948550613490970

Gistelinck, F., Loeys, T., Decuyper, M., \& Dewitte, M. (2018). Indistinguishability tests in the actor-partner interdependence model. British Journal of Mathematical and Statistical Psychology. https://doi.org/10.1111/bmsp.12129

Guenole, N., \& Brown, A. (2014). The consequences of ignoring measurement invariance for path coefficients in structural equation models. Frontiers in Psychology, 5.

Haavio-Mannila, E., \& Kontula, O. (1997). Correlates of Increased Sexual Satisfaction. Archives of Sexual Behavior, 26(4), 399419. https://doi.org/10.1023/A:1024591318836
Hill, C. T., Rubin, Z., \& Peplau, L. A. (1976). Breakups before marriage: The end of 103 affairs. Journal of Social Issues, 32(1), 147-168. https://doi.org/10.1111/j.1540-4560.1976.tb02485.x

Holmberg, D., \& Blair, K. L. (2009). Sexual desire, communication, satisfaction, and preferences of men and women in same-sex versus mixed-sex relationships. Journal of Sex Research, 46(1), 57-66. https://doi.org/10.1080/00224490802645294

Hong, S., \& Kim, S. (2018). Comparisons of Multilevel Modeling and Structural Equation Modeling Approaches to Actor-Partner Interdependence Model. Psychological Reports. https://doi.org/10.1177/0033294118766608

Hu, L., \& Bentler, P. M. (1999). Cutoff criteria for fit indexes in covariance structure analysis: Conventional criteria versus new alternatives. Structural Equation Modeling, 6, 1-55.

Joel, S., Eastwick, P. W., \& Finkel, E. J. (2018). Open Sharing of Data on Close Relationships and Other Sensitive Social Psychological Topics: Challenges, Tools, and Future Directions. Advances in Methods and Practices in Psychological Science, 1(1), 86-94. https://doi.org/10.1177/2515245917744281

John, L. K., Loewenstein, G., \& Prelec, D. (2012). Measuring the Prevalence of Questionable Research Practices with Incentives for Truth Telling. Psychological Science, 23(5), 524-532. https://doi.org/10.1177/0956797611430953

Jorgensen, T. D., Pornprasertmanit, S., Schoemann, A. M., \& Rosseel, Y. (2018). semTools: Useful tools for structural equation modeling. $\mathrm{R}$ package version 0.5-1. Retrieved fromhttps://CRAN.R-project.org/package $=$ semTools

Jorgensen, T. D., Kite, B. A., Chen, P.-Y., \& Short, S. D. (2018). Permutation randomization methods for testing measurement equivalence and detecting differential item functioning in multiple-group confirmatory factor analysis. Psychological Methods, 23, 708-728. doi: 10.1037/met0000152.

Karantzas, G. C., Feeney, J. A., \& Wilkinson, R. (2010). Is less more? Confirmatory factor analysis of the Attachment Style Questionnaires. Journal of Social and Personal Relationships, 27(6), 749-780. https://doi.org/10.1177/0265407510373756

Keller, A., McGarvey, E. L., \& Clayton, A. H. (2006). Reliability and Construct Validity of the Changes in Sexual Functioning Questionnaire Short-Form (CSFQ-14). Journal of Sex \& Marital Therapy, 32(1), 43-52. https://doi.org/10.1080/00926230500232909

Kenny, D. A., Kashy, D. A., \& Cook, W. L. (2006). Dyadic Data Analysis. New York, NY: Guilford Press.

Kiecolt-Glaser, J. K., \& Newton, T. L. (2001). Marriage and health: His and hers. Psychological Bulletin, 127(4), 472-503. https://doi.org/10.1037/0033-2909.127.4.472

Kunce, L. J., \& Shaver, P. R. (1994). An attachment-theoretical approach to caregiving in romantic relationships. In $\mathrm{K}$. Bartholomew \& D. Perlman (Eds.), Attachment processes in adulthood. (pp. 205-237). London: Jessica Kingsley Publishers.

Lawrance, K.-A., \& Byers, E. S. (1995). Sexual satisfaction in longterm heterosexual relationships: The interpersonal exchange model of sexual satisfaction. Personal Relationships, 2(4), 267 285. https://doi.org/10.1111/j.1475-6811.1995.tb00092.x 
Ledermann, T., \& Kenny, D. A. (2017). Analyzing dyadic data with multilevel modeling versus structural equation modeling: A tale of two methods. Journal of Family Psychology, 31(4), 442-452. https://doi.org/10.1037/fam0000290

Ledermann, T., \& Macho, S. (2014). Analyzing change at the dyadic level: The common fate growth model. Journal of Family Psychology, 28(2), 204-213. https://doi.org/10.1037/a0036051

Ledermann, T., \& Kenny, D. A. (2012). The common fate model for dyadic data: Variations of a theoretically important but underutilized model. Journal of Family Psychology, 26(1), 140148. https://doi.org/10.1037/a0026624

Ledermann, T., Macho, S., \& Kenny, D. A. (2011). Assessing Mediation in Dyadic Data Using the Actor-Partner Interdependence Model. Structural Equation Modeling: A Multidisciplinary Journal, 18(4), 595-612. https://doi.org/10.1080/10705511.2011.607099

Little, T. D. (2013). Longitudinal Structural Equation Modeling. New York, NY: Guilford Press.

Little, T. D., Cunningham, W. A., Shahar, G., \& Widaman, K. F. (2002). To parcel or not to parcel: Exploring the question, weighing the merits. Structural Equation Modeling, 9(2), 151173.

Locke, H. J., \& Wallace, K. M. (1959). Short marital-adjustment and prediction tests: Their reliability and validity. Marriage \& Family Living, 21, 251-255. https://doi.org/10.2307/348022

Loeys, T., \& Molenberghs, G. (2013). Modeling actor and partner effects in dyadic data when outcomes are categorical. Psychological Methods, 18(2), 220-236. https://doi.org/10.1037/a0030640

Mancosu, M., \& Vezzoni, C. (2018). Actor-partner interdependence models (APIM) and voting behavior: Methodology and applications. Political Psychology, 39(1), 163-176. https://doi.org/10.1111/pops. 12400

Maxwell, J. A., Muise, A., MacDonald, G., Day, L. C., Rosen, N. O., \& Impett, E. A. (2017). How implicit theories of sexuality shape sexual and relationship well-being. Journal of Personality and Social Psychology, 112(2), 238-279. https://doi.org/10.1037/pspi0000078.supp

Maxwell, S. E. (2004). The Persistence of Underpowered Studies in Psychological Research: Causes, Consequences, and Remedies. Psychological Methods, 9(2), 147-163. https://doi.org/10.1037/1082-989X.9.2.147.

McCoach, D. B., \& Adelson, J. L. (2010). Dealing with dependence (Part I): Understanding the effects of clustered data. Gifted Child Quarterly, 54(2), 152-155. https://doi.org/10.1177/0016986210363076

Meade, A. W., \& Lautenschlager, G. J. (2004). A Comparison of Item Response Theory and Confirmatory Factor Analytic Methodologies for Establishing Measurement Equivalence/lnvariance. Organizational Research Methods, 7(4), 361-388. https://doi.org/10.1177/1094428104268027

Meehl, P. E. (1990a). Why summaries of research on psychological theories are often uninterpretable. Psychological Reports, 66(1), 195-244. https://doi.org/10.2466/PR0.66.1.195-244

Meehl, P. E. (1990b). Appraising and amending theories: The strategy of Lakatosian defense and two principles that warrant it. Psychological Inquiry, 1(2), 108-141. https://oi.org/10.1207/s15327965pli0102
Meredith, W. (1993). Measurement invariance, factor analysis and factorial invariance. Psychometrika, 58(4), 525-543. https://doi.org/10.1007/BF02294825

Mills, J., Clark, M. S., Ford, T. E., \& Johnson, M. (2004). Measurement of communal strength. Personal Relationships, 11(2), 213-230. https://doi.org/10.1111/j.14756811.2004.00079.x

Millsap, R. E. (2011). Statistical approaches to measurement invariance. New York, NY: Routledge/Taylor \& Francis Group.

Muise, A., Impett, E. A., Kogan, A., \& Desmarais, S. (2013). Keeping the spark alive: Being motivated to meet a partner's sexual needs sustains sexual desire in long-term romantic relationships. Social Psychological and Personality Science, 4(3), 267-273. https://doi.org/10.1177/1948550612457185

Muise, A., Christofides, E., \& Desmarais, S. (2009). More information than you ever wanted: Does Facebook bring out the green-eyed monster of jealousy? CyberPsychology \& Behavior, 12(4), 441-444. https://doi.org/10.1089/cpb.2008.0263

Neff, L. A., \& Karney, B. R. (2005). Gender Differences in Social Support: A Question of Skill or Responsiveness? Journal of Personality and Social Psychology, 88(1), 79-90. https://doi.org/10.1037/0022-3514.88.1.79

Nelson, L. D., Simmons, J., \& Simonsohn, U. (2018). Psychology's Renaissance. Annual Review of Psychology, 69(1), 511-534. https://doi.org/10.1146/annurev-psych-122216-011836

Olsen, J. A., \& Kenny, D. A. (2006). Structural equation modeling with interchangeable dyads. Psychological Methods, 11(2), 127141. https://doi.org/10.1037/1082-989X.11.2.127

Penke, L., \& Asendorpf, J. B. (2008). Beyond global sociosexual orientations: A more differentiated look at sociosexuality and its effects on courtship and romantic relationships. Journal of Personality and Social Psychology, 95, 1113-1135.

Pinkerton, S. D., Cecil, H., Bogart, L. M., \& Abramson, P. R. (2003). The pleasures of sex: An empirical investigation. Cognition \& Emotion, 17(2), 341.

Pinney, E. M., Gerrard, M., \& Denney, N. W. (1987). The Pinney Sexual Satisfaction Inventory. Journal of Sex Research, 23(2), 233-251. https://doi.org/10.1080/00224498709551359

Putnick, D. L., \& Bornstein, M. H. (2016). Measurement invariance conventions and reporting: The state of the art and future directions for psychological research. Developmental Review, 41, 71-90. https://doi.org/10.1016/j.dr.2016.06.004

R Core Team (2018). R: A language and environment for statistical computing. R Foundation for Statistical Computing, Vienna, Austria. URL https://www.R-project.org/.

Rhemtulla, M., Brosseau-Liard, P. É., \& Savalei, V. (2012). When can categorical variables be treated as continuous? A comparison of robust continuous and categorical SEM estimation methods under suboptimal conditions. Psychological Methods, 17(3), 354-373.

Rosenthal, R. (1979). The "file drawer problem" and tolerance for null results. Psychological Bulletin, 86(3), 638-641.

Rosseel, Y. (2012). lavaan: An R Package for Structural Equation Modeling. Journal of Statistical Software, 48(2), 1-36. http://www.jstatsoft.org/v48/i02/. 
Rubin, Z. (1970). Measurement of romantic love. Journal of Personality and Social Psychology, 16(2), 265-273. https://doi.org/10.1037/h0029841

Rusbult, C. E., Martz, J. M., \& Agnew, C. R. (1998). The Investment Model Scale: Measuring commitment level, satisfaction level, quality of alternatives, and investment size. Personal Relationships, 5(4), 357-391. https://doi.org/10.1111/j.1475-6811.1998.tb00177.x

Rye, B. J., Serafini, T., \& Bramberger, T. (2015). Erotophobic or erotophilic: What are young women's attitudes towards BDSM? $\begin{array}{llll}\text { Psychology \& Sexuality, 6(4), 340-356. } & \text {. }\end{array}$ https://doi.org/10.1080/19419899.2015.1012108

Sakaluk, J. K. (2019). Expanding Statistical Frontiers in Sexual Science: Taxometric, Invariance, and Equivalence Testing. Journal of Sex Research. doi: 10.1080/00224499.2019.1568377

Salisbury, C. M. A., \& Fisher, W. A. (2014). "Did you come?" A qualitative exploration of gender differences in beliefs, experiences, and concerns regarding female orgasm occurrence during heterosexual sexual interactions. Journal of Sex Research, 51(6), 616-631. https://doi.org/10.1080/00224499.2013.838934

Schimmack, U. (2012). The ironic effect of significant results on the credibility of multiple-study articles. Psychological Methods, 17(4), 551-566. https://doi.org/10.1037/a0029487

Schmitt, N., Golubovich, J., \& Leong, F. T. L. (2011). Impact of measurement invariance on construct correlations, mean differences, and relations with external correlates: An illustrative example using big five and RIASEC measures. Assessment, 18(4), 412-427. https://doi.org/10.1177/1073191110373223

Schrodt, P., Ledbetter, A. M., Jernberg, K. A., Larson, L., Brown, N., \& Glonek, K. (2009). Family communication patterns as mediators of communication competence in the parent - child relationship. Journal of Social and Personal Relationships, 26(6-7), 853-874. https://doi.org/10.1177/0265407509345649

Shadish, W. R., Cook, T. D., \& Campbell, D. T. (2002). Experimental and quasi-experimental designs for generalized causal inference. Boston, MA: Houghton, Mifflin and Company.

Sibley, C. G., Fischer, R., \& Liu, J. H. (2005). Reliability and Validity of the Revised Experiences in Close Relationships (ECR-R) Self-Report Measure of Adult Romantic Attachment. Personality and Social Psychology Bulletin, 31(11), 1524-1536. https://doi.org/10.1177/0146167205276865

Simpson, J. A., \& Gangestad, S. W. (1991). Individual differences in sociosexuality: Evidence for convergent and discriminant validity. Journal of Personality and Social Psychology, 60(6), 870-883. https://doi.org/10.1037/0022-3514.60.6.870

South, S. C., Krueger, R. F., \& Iacono, W. G. (2009). Factorial invariance of the Dyadic Adjustment Scale across gender. Psychological Assessment, 21(4), 622-628. https://doi.org/10.1037/a0017572

Spanier, G. B. (1976). Measuring dyadic adjustment: New scales for assessing the quality of marriage and similar dyads. Journal of Marriage and the Family, 38, 15-28.

Spellman, B. A. (2015). A Short (Personal) Future History of Revolution 2.0. Perspectives on Psychological Science, 10(6), 886-899. https://doi.org/10.1177/1745691615609918
Sprecher, S. (2002). Sexual Satisfaction in Premarital Relationships: Associations with Satisfaction, Love, Commitment, and Stability. Journal of Sex Research, 39(3), 190-196. Retrieved from http://www.jstor.org/stable/3813614

Steinmetz, H. (2013). Analyzing observed composite differences across groups: Is partial measurement invariance enough? Methodology: European Journal of Research Methods for the Behavioral and Social Sciences, 9(1), 1-12. https://doi.org/10.1027/1614-2241/a000049

Stephenson, K. R., Ahrold, T. K., \& Meston, C. M. (2011). The association between sexual motives and sexual satisfaction: Gender differences and categorical comparisons. Archives of Sexual Behavior, 40(3), 607-618. https://doi.org/10.1007/s10508-010-9674-4

Sterba, S. K. (2011). Implications of parcel-allocation variability for comparing fit of item-solutions and parcel-solutions. Structural Equation Modeling, 18(4), 554-577. doi:10.1080/10705511.2011.607073

Sterba, S. K. \& MacCallum, R. C. (2010). Variability in parameter estimates and model fit across random allocations of items to parcels. Multivariate Behavioral Research, 45(2), 322-358. doi:10.1080/00273171003680302

Sternberg, R. J. (2006). The Nature of Creativity. Creativity Research Journal, 18(1), 87-98.

Stokes, J. E. (2017). Do "His" and "Her" Marriages Influence One Another? Contagion in Personal Assessments of Marital Quality among Older Spouses over a Four-Year Span. Social Psychology Quarterly, 80(2), 204-215. https://doi.org/10.1177/0190272517701701

Tan, K., Jarnecke, A. M., \& South, S. C. (2017). Impulsivity, communication, and marital satisfaction in newlywed couples: Impulsivity and marital relationships. Personal Relationships, 24(2), 423-439. doi:10.1111/pere. 12190

van Anders, S. M. (2015). Beyond sexual orientation: Integrating gender/sex and diverse sexualities via sexual configurations theory. Archives of Sexual Behavior, 44(5), 1177-1213. https://doi.org/10.1007/s10508-015-0490-8

Vandenberg, R. J., \& Lance, C. E. (2000). A Review and Synthesis of the Measurement Invariance Literature: Suggestions, Practices, and Recommendations for Organizational Research. Organizational Research Methods, 3(1), 4-70. https://doi.org/10.1177/109442810031002

Vazire, S. (2018). Implications of the Credibility Revolution for Productivity, Creativity, and Progress. Perspectives on Psychological Science, 13(4), 411-417. https://doi.org/10.1177/1745691617751884

Vohs, K. D., Catanese, K. R., \& Baumeister, R. F. (2004). Sex in "His" Versus "Her" Relationships. In J. H. Harvey, A. Wenzel, \& S. Sprecher (Eds.), The handbook of sexuality in close relationships. (pp. 455-474). Mahwah, NJ: Lawrence Erlbaum Associates Publishers.

Wei, M., Russell, D. W., Mallinckrodt, B., \& Vogel, D. L. (2007). The Experiences in Close Relationship Scale (ECR)-short form: Reliability, validity, and factor structure. Journal of Personality Assessment, $88(2), \quad$ 187-204. https://doi.org/10.1080/00223890701268041 
West, T. V., \& Kenny, D. A. (2011). The truth and bias model of judgment. Psychological Review, 118(2), 357-378. https://doi.org/10.1037/a0022936

Wheeler, L., Reis, H., \& Nezlek, J. B. (1983). Loneliness, social interaction, and sex roles. Journal of Personality and Social Psychology, 45(4), 943-953. https://doi.org/10.1037/00223514.45.4.943

Whisman, M. A., \& Li, A. (2015). Assessment of positive and negative relationship adjustment in marriage. Personal Relationships, 22(4), https://doi.org/10.1111/pere.12103
Widaman, K. F., \& Reise, S. P. (1997). Exploring the measurement invariance of psychological instruments: Applications in the substance use domain. In K. J. Bryant, M. Windle, \& S. G. West (Eds.), The science of prevention: Methodological advances from alcohol and substance abuse research. (pp. 281-324). Washington, DC: American Psychological Association.

Zandbergen, D. L., \& Brown, S. G. (2015). Culture and gender differences in romantic jealousy. Personality and Individual Differences, 72 , 122-127. 
Table 1

Summary of Relationship Measure Domains and Example Desirable Measures for Dyadic Invariance Testing

\begin{tabular}{|c|c|c|}
\hline Domain & Scale/Measure & Citation \\
\hline \multirow[t]{5}{*}{$\begin{array}{l}\text { Relationship } \\
\text { Well-Being }\end{array}$} & Investment Model Scale & Rusbult, Martz, \& Agnew, 1998 \\
\hline & $\begin{array}{l}\text { Perceived Relationship Quality } \\
\text { Components (PRQC) Inventory }\end{array}$ & Fletcher, Simpson, \& Thomas, 2000 \\
\hline & Dyadic Adjustment Scale (DAS) & Spanier, 1976 \\
\hline & Couple Satisfaction Index (CSI) & Funk \& Rogge, 2007 \\
\hline & Marital Adjustment Test (MAT) & Locke \& Wallace, 1959 \\
\hline \multirow[t]{8}{*}{ Sexuality } & $\begin{array}{l}\text { Sociosexual Orientation Inven- } \\
\text { tory (SOI) }\end{array}$ & Simpson \& Gangestad, 1991 \\
\hline & $\begin{array}{l}\text { Sociosexual Orientation Inven- } \\
\text { tory-Revised (SOI-R) }\end{array}$ & Penke \& Asendorpf, 2008 \\
\hline & Infidelity Dilemma & $\begin{array}{l}\text { Buss, Larsen, Westen \& Semmelroth, } \\
1992\end{array}$ \\
\hline & Infidelity Dilemma & Buss et al., 1999 \\
\hline & $\begin{array}{l}\text { Changes in Sexual Functioning } \\
\text { Questionnaire (CSFQ-14) }\end{array}$ & Keller, McGarvey \& Clayton, 2006 \\
\hline & $\begin{array}{l}\text { Pinney Sexual Satisfaction In- } \\
\text { ventory (PSSI) }\end{array}$ & Pinney, Gerard \& Denney, 1987 \\
\hline & $\begin{array}{l}\text { Interpersonal Exchange Model } \\
\text { of Sexual Satisfaction (IEMSS) }\end{array}$ & Lawrance \& Byers, 1995 \\
\hline & Erotophilia-Erotophobia & Fisher, Byrne, White \& Kelley, 1988 \\
\hline
\end{tabular}


Erotophilia-Erotophobia

Sexual Systems Functioning Scale (SFSS)

Sexual Communal Strength (SCS)
Rye, Serafini \& Bramberger

Birnbaum, Mikulincer, Szepsenwol, Shaver \& Mizrahi, 2014

Muise, Impett, Kogan \& Desmarais, 2013

Relationship Experiences in Close RelationPersonality ships (ECR)

Caregiving Questionnaire (CQ)

Relationship Closeness Inventory
Brennan, Clark \& Shaver, 1998

Kunce \& Shaver, 1994

Mills, Clark, Ford \& Johnson, 2004 
Table 2

Table of Summary Results from Dyadic Invariance Tests

\begin{tabular}{|c|c|c|c|c|c|}
\hline Measure & $\begin{array}{l}\text { Measure Do- } \\
\text { main }\end{array}$ & $\begin{array}{l}n d y a d s / \text { num- } \\
\text { ber of sam- } \\
\text { ples included }\end{array}$ & $\begin{array}{l}\text { Dyadic Con- } \\
\text { figural Invari- } \\
\text { ance? }\end{array}$ & $\begin{array}{l}\text { Dyadic Load- } \\
\text { ing Invari- } \\
\text { ance? }\end{array}$ & $\begin{array}{l}\text { Dyadic Inter- } \\
\text { cept Invari- } \\
\text { ance? }\end{array}$ \\
\hline $\begin{array}{l}\text { Example } \\
\text { Measure "X" }\end{array}$ & $\begin{array}{l}\text { Relationship } \\
\text { Well-Being }\end{array}$ & $400 / 2$ & $\checkmark$ & $\mathrm{X}$ & $X$ \\
\hline $\begin{array}{l}\text { Example } \\
\text { Measure "Y" }\end{array}$ & $\begin{array}{l}\text { Relationship } \\
\text { Well-Being }\end{array}$ & $200 / 1$ & $\sqrt{ }$ & $\checkmark$ & $\sqrt{ }$ \\
\hline $\begin{array}{l}\text { Example } \\
\text { Measure " } Z \text { " }\end{array}$ & $\begin{array}{l}\text { Relationship } \\
\text { Well-Being }\end{array}$ & $1000 / 5$ & $\sqrt{ }$ & $P$ & $\sqrt{ }$ \\
\hline$\cdots$ & $\cdots$ & $\cdots$ & $\cdots$ & $\cdots$ & $\cdots$ \\
\hline
\end{tabular}

Note. $\sqrt{ }=$ invariance level tenable; $\mathrm{X}=$ invariance level not supported; $\boldsymbol{P}=$ partial invariance level tenable. 

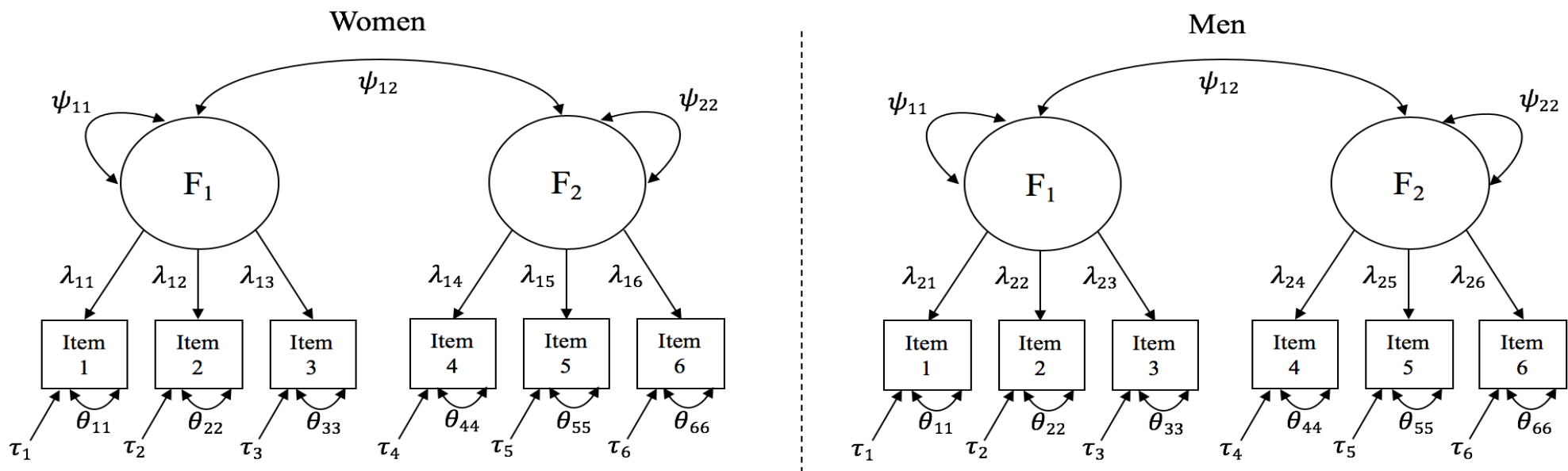

Figure 1. A hypothetical two-factor measure of attachment insecurity for heterosexual romantic partners $\left(\mathrm{F}_{1}=\mathrm{Anxiety}, \mathrm{F}_{2}=\mathrm{Avoid}-\right.$ ance). 


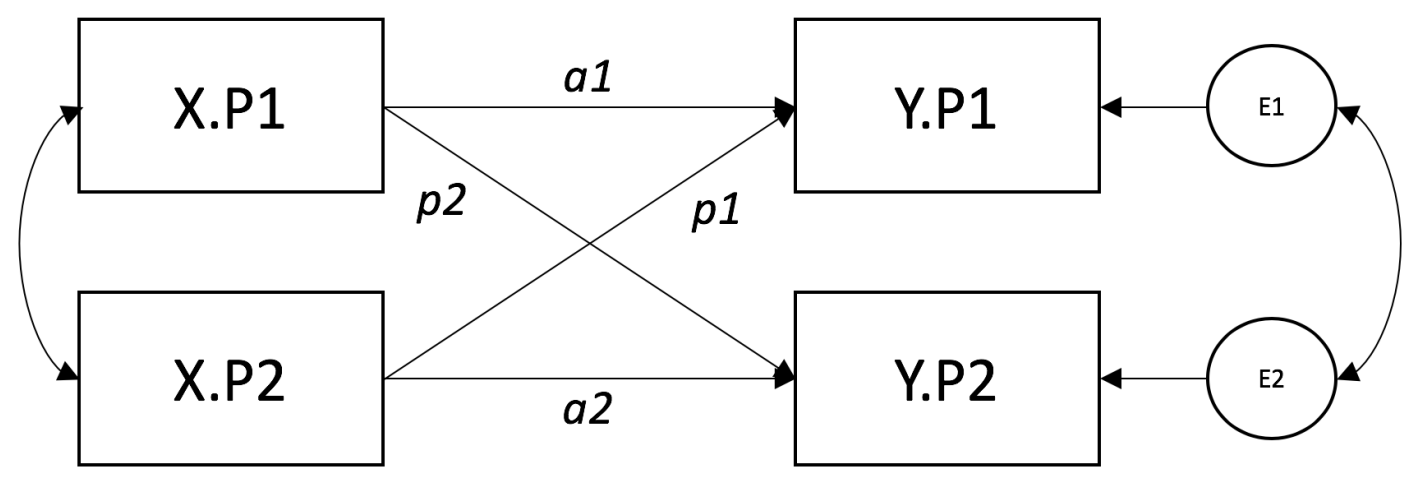

Figure 2. A generic observed-level (non-latent) distinguishable actor-partner interdependence model. 


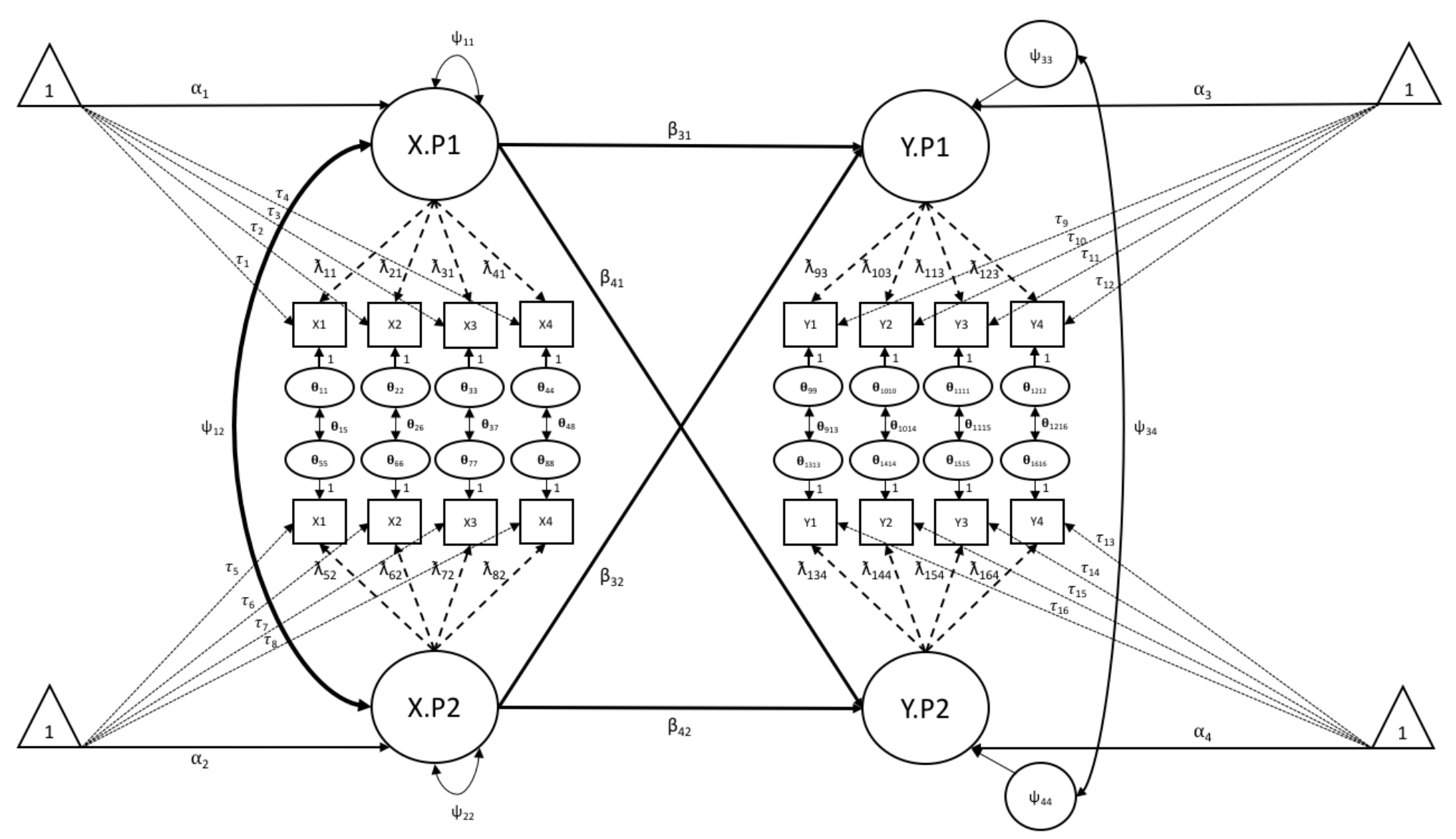

Figure 3. A latent distinguishable APIM with four indicators for $X$ and $Y$ that is configurally invariant between dyad partners. 


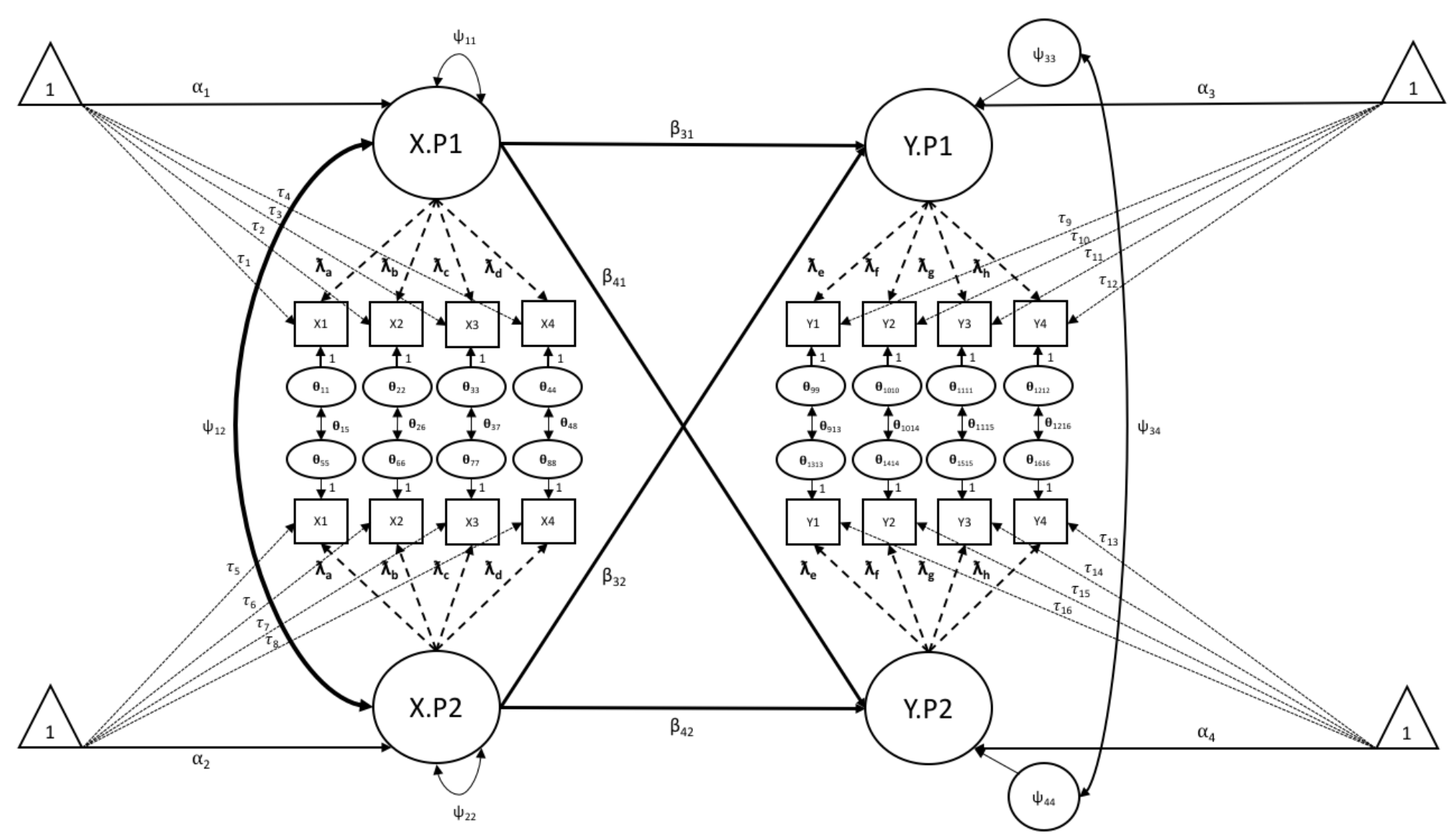

Figure 4. A latent distinguishable APIM with four indicators for $X$ and $Y$ that is constrained to loading equivalency between dyad partners. 


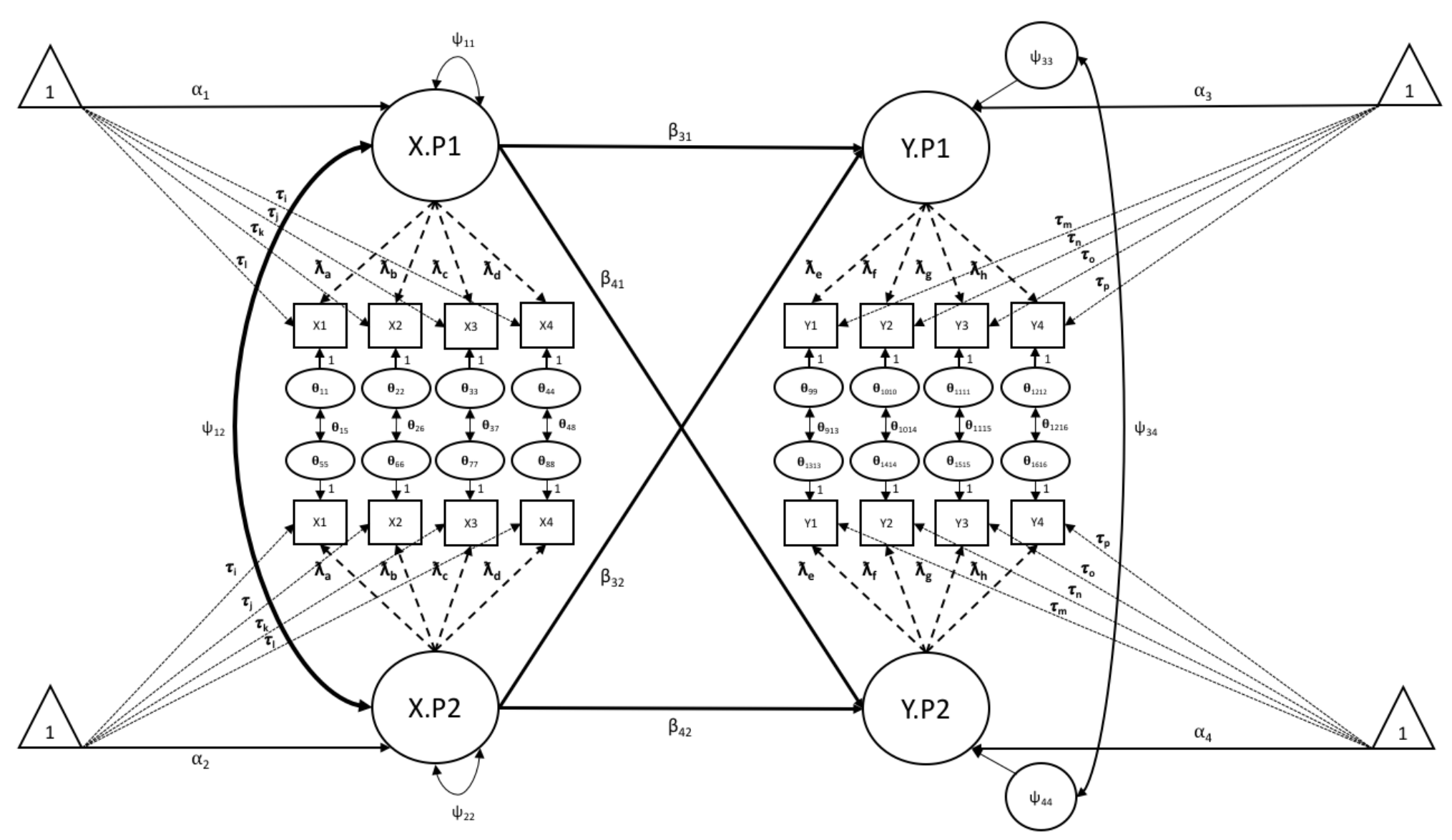

Figure 5. A latent distinguishable APIM with four indicators for $X$ and $Y$ that is constrained to loading and intercept equivalency between dyad partners. 